Please do not remove this page

RMIT

UNIVERSITY

\title{
Vibration modal analysis of defects in composite T-stiffened panels
}

Herman, Alexander; Orifici, Adrian; Mouritz, Adrian

https://researchrepository.rmit.edu.au/esploro/outputs/9921859402701341/filesAndLinks?institution=61RMIT_INST\&index=null

Herman, A., Orifici, A., \& Mouritz, A. (2013). Vibration modal analysis of defects in composite T-stiffened panels. Composite Structures, 104, 34-42. https://doi.org/10.1016/j.compstruct.2013.04.012

Document Version: Accepted Manuscript

Published Version: https://doi.org/10.1016/j.compstruct.2013.04.012

Repository homepage: https://researchrepository.rmit.edu.au

(C) 2013 Elsevier Ltd.

Downloaded On 2023/04/26 23:12:19 +1000

Please do not remove this page 
Thank you for downloading this document from the RMIT Research Repository.

The RMIT Research Repository is an open access database showcasing the research outputs of RMIT University researchers.

RMIT Research Repository: http://researchbank.rmit.edu.au/

\section{Citation:}

Herman, A, Orifici, A and Mouritz, A 2013, 'Vibration modal analysis of defects in composite T-stiffened panels', Composite Structures, vol. 104, pp. 34-42.

See this record in the RMIT Research Repository at:

http://researchbank.rmit.edu.au/view/rmit:22158

Version: Accepted Manuscript

Copyright Statement: (C) 2013 Elsevier Ltd

Link to Published Version:

http://dx.doi.org/10.1016/j.compstruct.2013.04.012 


\title{
VIBRATION MODAL ANALYSIS OF DEFECTS IN COMPOSITE T-STIFFENED PANELS
}

\author{
A.P. Herman, A.C. Orifici and A.P. Mouritz ${ }^{*}$ \\ RMIT University, School of Aerospace, Mechanical and Manufacturing Engineering, \\ Melbourne, PO Box 71, Bundoora, VIC 3083
}

\begin{abstract}
This paper presents a numerical and experimental investigation into the detection of defects in composite T-stiffened panels using vibration modal analysis. The analysis was performed on carbon fibre/epoxy laminate panels containing delamination cracks or porosity. Experimental testing revealed that vibrational excitation of the defective panels altered the vibration mode response, measured using scanning laser vibrometry. Testing showed that changes to the mode shape curvature of the lower order vibrational modes was the most reliable indicator of damage within the stiffened panel whereas high order modes could not be used to detect damage. This was confirmed with vibrational analysis using finite element modelling, which also revealed that damage detection using vibration mode shape curvature analysis was not affected significantly by the defect location or the vibration excitation point in the stiffened panel.
\end{abstract}

\section{INTRODUCTION}

T-stiffened composite panels are used extensively in thin walled structures such as aircraft fuselage and wings, with the skin carrying membrane loads and the stiffeners carrying bending loading and resisting skin buckling. One problem encountered with stiffened panels is damage along the bond-line joining the skin and stiffener due to poor quality manufacturing or in-service damage. Examples of manufacturing damage are regions of high porosity or large voids and the most common case of in-service damage is delamination cracking caused by over-loading, impact or environmental degradation.

Damage in T-stiffened panels can be hard to detect using many conventional non-destructive inspection (NDI) methods, such as ultrasonics or thermography, due to the changes in section

\footnotetext{
* Corresponding author: A.P. Mouritz

Tel: +61 399256269

Fax: +61399256108

e-mail: adrian.mouritz@rmit.edu.au
} 
thickness along the skin/stiffener flange connection, within the web and, in particular, at the base of the stiffener. Short cracks and small regions of porosity can be difficult to detect using many NDI techniques, although the damage can significantly reduce the stiffness and ultimate load of T-bonded joints [1-4]. As a result, stiffened composite panels for aircraft are conservatively designed for high damage tolerance which adds significant weight to the structure. Many damage inspection techniques have been assessed for T-shaped composite joints, and some of these may be suitable for thin-skin stiffened panels. Compliance (stiffness-based) methods [3-6], strain monitoring using Bragg grating optical fibre sensors [7], and dynamic methods [1,8-15] have been used to detect delamination cracks in composite panels, joints or bonded repairs, although these methods have not been evaluated for the detection of porosity and voids.

Another promising damage detection technique for composite structures is vibration modal analysis [17-31]. This technique involves transmitting elastic stress waves of different frequencies into the structure. The frequencies, displacements and shapes of the vibrational modes within the structure are measured using equipment such as Scanning Laser Doppler Vibrometry (SLV), and any change in the modal properties compared to the defect-free structure can be used to indicate the presence and localation of damage. For example, Ghoshal et al. [18-19] used SLV to detect delaminations in a curved fibreglass composite plate and honeycomb panel. As another example, Staszewski et al. [22-25] investigated the use of guided waves to locate damage in composite aerostructures based on an actuator-sensor system at different points across the structure. This method employed SLV to measure the dynamic response of the structure and estimate the severity of delamination damage in a flat composite panel. Numerous studies have proven that vibration modal analysis can detect delaminations in flat or slightly curved composite panels and more complex structures, however the method has not been evaluated for detecting delaminations in T-stiffened panels. Furthermore, no studies have reported the ability to detect porosity within composite structures using vibration modal analysis.

The aim of this paper is to assess the vibration modal analysis technique for the detection of damage in T-stiffened composite panels. This type of panel was selected because of its common use in aircraft structures and other thin-walled structures. The stiffened panels were fabricated from carbon fibre/epoxy laminate, and the capability of vibration modal analysis to detect porosity and delamination cracks along the interface between the base skin and 
stiffener was assessed. Porosity and delamination were investigated as they are the most likely to occur in stiffened panels due to poor quality manufacturing and in-service damage, respectively. Experimental tests were performed on pristine and defective panels to measure the vibration response induced by a mechanical shaker and measured using SLV. Finite element modelling was performed to numerically assess the sensitivity of vibration modal analysis to detect delamination or porosity located at different regions within stiffened panels. The purpose of the experimental and modelling work was to assess the capabilities and limitations of vibration modal analysis for the detection of bond-line defects in stiffened panels, which are difficult to find using other non-destructive inspection methods, such as thermography and ultrasonics.

\section{EXPERIMENTAL TESTING}

\subsection{T-Stiffened Composite Panels}

T-stiffened panels were fabricated using unidirectional carbon fibre/epoxy prepreg tape (VTM264, Advanced Composites Group). The geometry and dimensions of the panel specimens is shown in Figure 1. The base skin, stiffener and flange were fabricated using the carbon/epoxy tape arranged in a $[90 / 0 / 90 / 0 / 90]_{\text {s }}$ ply pattern. The skin and stiffener were both $2 \mathrm{~mm}$ thick, and the stiffener flange reduced in thickness from the web at a $45^{\circ}$ angle with the skin. The $\Delta$-fillet region at the stiffener base was filled with unidirectional carbon/epoxy tape to avoid the formation of a porous or resin-rich region.

An artificial delamination or porous region was created from the edge to the mid-way point along one flange (as indicated in Figure 1). The delamination or porous region extended across the entire width of the panel. The delamination was artificially created by inserting non-stick PTFE film ( $5 \mu \mathrm{m}$ thick) to stop the flange from bonding to the base skin during the curing process. The porosity was introduced using phenolic microballoons with an external diameter between 1 and $50 \mu \mathrm{m}$, and a mean diameter of $12 \mu \mathrm{m}$. The microballoons were dispersed evenly over the defective region. A pristine panel, delaminated panel and porous panel were manufactured via curing within an autoclave at $120^{\circ} \mathrm{C}$ and $620 \mathrm{kPa}$ for one hour. Film adhesive was not used in the co-cure bonding of the stiffener flanges to the base skin. 


\subsection{Vibration Testing of T-Stiffened Panels}

The T-stiffened composite panels were mounted to a fixture to perform scanning laser vibrometry to measure the vibration response, as shown in Figure 2. The panels were suspended above a mechanical shaker using thin elastic bands that did not affect the vibration response. A mechanical shaker was used to generate sinusoidal waves at increasing frequencies $(0-10 \mathrm{kHz})$ which were transmitted into the panel via a thin connecting rod. The excitation point of the panels was either near one edge of the skin (Figure 2b) or at the end of the stiffener (Figure 2c). The vertical displacements of the panels for each modal frequency were measured using an SLV (Polytec PSV-400). The panels were scanned using the laser vibrometer from the skin side (Figure 2b) and the stiffener side (Figure 2c). The mode shape displacement (MSD) of the vibrational modes were measured at 218 individual scan points along a length of nearly $200 \mathrm{~mm}$ from both sides of the panel. This test configuration provided good repeatability in the experimental results measured using the SLV. For example, Figure 3 shows twelve vertical velocity-frequency profiles measured for the pristine stiffened panel under identical conditions, and there is good consistency in the results.

\section{FINITE ELEMENT ANALYSIS}

A finite element model of the pristine and defective T-stiffened panels was created using MSC.Patran and analysed in MD.Nastran. The model had the same dimensions, cross-ply pattern, and boundary conditions as the experimental test panels, although the bond-line between the skin and flange was assumed to be a thin epoxy film adhesive whereas the specimens were joined via a thin epoxy later formed by co-curing (without film adhesive). The orthotropic material properties used in the modelling of the T-stiffened panels are given in Table 1. A model of the panels was created using 8-node three-dimensional solid elements with the orientations and thickness of the carbon/epoxy plies matching those of the test specimens. Figure 4 shows the meshing of the T-stiffened panel at the web region and skin/flange taper region. A mesh dependence study was performed to identify the optimum element sizes to achieve convergence in the vibrational displacement of the panel [16]. The Tstiffened panel was constructed using over 42,000 elements with nearly 164,000 nodes.

The front and rear faces of the T-stiffened panels used in the modelling were fixed such that movement was only allowed in the cross-section plane, with out-of-plane displacement restrained. The model was excited using varying frequencies $(0-10 \mathrm{kHz})$ at points near the 
edge of the base skin or the end of the stiffener; and these were the same frequency range and excitation locations used in the experimental tests.

Several types of damage in the T-stiffened panel were modelled. Firstly, the delamination and porous regions extending from the outer edge to the mid-way point to one of the stiffeners (Figure 1) were analysed to validate the finite element model. The delamination was modelled using unconnected coincident nodes along the damage length. The porosity was modelled by reducing the Young's modulus of the bond-line region by 10\% compared to the pristine bondline. This value of $10 \%$ was selected as an arbitrary value because the Young's modulus of composite materials can be reduced over a wide range depending on the void content, void size and the external loading condition (e.g. [32-33]). These two cases of delamination and porosity damage were used to validate the model in comparison with experimental results, after which other damage cases were analysed.

\section{RESULTS AND DISCUSSION}

\subsection{Experimental Testing and Analysis}

The mode shape displacements for the T-stiffened panels were measured using the SLV, and there was no significant difference between the pristine and defective specimens. Figure 5 shows the normalised displacement along the length of the undamaged panel and the panels containing a delamination or porous region along the skin/flange bond-line. The data points within a single modal measurement were all normalised by a divisor defined as the distance from zero to the first local maximum measured in the vertical axis. There is no significant difference between the three types of panel, including in the damage region. Based on this, the MSD response is not considered suitable as a reliable indicator of damage for these specimens. The displacement measurements shown in Figure 5 were taken along the skin surface (i.e. the case shown in Figure 2a), and similar measurements along the stiffener side of the panel (i.e. Figure 2b) also failed to reveal any differences in the MSD profiles between the pristine and defective specimens. This finding agrees with other studies that have shown that the MSD response is not affected significantly by damage within flat composite panels containing delaminations [18-21].

Analysis of the mode shape curvature (MSC) profiles proved more promising in the detection of damage. The difference between the MSC profile for the defective panel and the MSC profile for the pristine panel (for the same mode number) was used to identify the location of 
damage. Figure 6 shows typical MSC-difference profiles along the length of the delaminated and porous panels when measured using an SLV from the skin side. The profiles have been normalised to the peak MSC-difference value, and they were measured for the first modal vibration (mode 1), defined as one-half sine wave. The location of the delamination damage was accurately detected by the large spike in the MSC-difference profile, which was due to damping of the mode 1 vibrational response by the large loss in local stiffness over the region of the crack. The MSC-difference method was also able to detect the porosity, however the central zone of the porous region was predicted to be about $30 \mathrm{~mm}$ from the actual central location. This inaccuracy may arise due to the weaker vibration damping effect of the porous region compared to that of the delamination crack, which is supported by the finding that the maximum MSC-difference value in the damaged region was about four times lower in the porous panel compared to the delaminated panel. The experimental testing also revealed that the MSC-difference method could detect delamination damage and porosity when the Tstiffened panels were inspected using SLV from the stiffener side, as shown in Figure 7.

The sensitivity of the MSC-difference method for the detection of delamination damage and porosity in the T-stiffened panels decreased rapidly with higher order vibrational modes. For example, Figure 8 shows the MSC-difference profile for the delaminated panel measured for

mode 3 , and two large spikes were recorded inside and outside of the damaged region. This is different to the profile measured for the mode 1 vibration (Figure 6a), which is centred within the actual delaminated region. This reveals that the accuracy of the MSC-difference method in the detection and location of damage within T-stiffened panels is the most sensitive and accurate when the lowest vibration mode is analysed.

\subsection{Finite Element Analysis}

The finite element model of the T-stiffened panel was validated by comparing the calculated vibrational displacements and mode shape curvature profiles against those measured experimentally using the SLV method. Figure 9 compares the mode shape displacements of the pristine panel for modes 1,2 and 3, calculated using the FE model and measured experimentally. The agreement between the calculated and measured displacement profiles and modal frequencies was good (less than 10\% difference). Good agreement was also found between the calculated and measured higher-order modes $(4,5$ and 6$)$, which revealed that the FE model can accurately predict the vibrational displacement response of the stiffened panel. The solid curves in Figure 6 and Figure 7 show the MSC-difference profiles for the 
delaminated and porous panels calculated using the FE model. The agreement with the measured profiles for both types of defective panel was good, although the FEA profile for the delamination measured from the stiffener side showed twin peaks (rather than a single peak) at the damage location. The comparison between the measured and calculated MSCdifference profiles reveals that the FE method can be used to assess the capability of the vibration modal analysis technique for damage detection in T-stiffened composite panels.

Using the validated FE model, a parametric study was performed into the capability of the MSC-difference method to detect damage in the T-stiffened panels. The effect of the input location on the vibrational modes was investigated by calculating the MSC-difference profiles for the panel excited at five points, as shown in Figure 10. It was found that the spike in the MSC-difference profile occurred at the damage location regardless of the vibration input location, as shown for the case of porosity in Figure 10b. This was also found with the experimental tests, where the excitation point along the skin did not significantly alter the MSC-difference profile. The insensitivity of the MSC-difference profiles to the excitation location indicates that any point along the panel can be used to input the vibration waves with no significant loss in damage detection resolution.

The FE model was used to assess whether vibration modal analysis can detect delaminations and porosity at different locations in the stiffened panel, as indicated in Figure 11. The locations considered were enclosed damage along the skin/stiffener bond-line, within the web region, and in the $\Delta$-fillet region. Figure 12 shows MSC-difference profiles for the defective panels calculated using the FE model. The model was able to detect delamination cracking and porosity along the skin/stiffener bond-line (Figure 12a) and along the web (Figure 12b). The position of the delamination crack was accurately determined (as shown earlier) whereas the location of porosity was not accurately predicted by the FE model. The model also revealed that detecting the damage location improved by using the lowest vibrational modes, with the higher modes proving to be less accurate in locating the damage. The model predicted that vibration modal analysis was unable to reliably detect damage within the $\Delta$ fillet region (Figure 12c). This is attributed to the small change in compliance of the $\Delta$-fillet region due to damage. The stiffness of this region in the pristine panel is very low compared to the stiffener, web and skin laminates. Therefore, the presence of damage in the $\Delta$-fillet region does not reduce significantly the local stiffness properties and consequently the 
difference in the MSC profiles between the pristine and defective panels was insignificant and below the resolution of the technique.

\section{CONCLUSIONS}

This study has proven that vibration modal analysis can be used to detect delamination cracks and regions of high porosity within T-stiffened composite panels. The mode shape displacements of the pristine and defective panels were found to be similar, and therefore this is not a suitable method for detecting damage. However, the difference in the mode shape curvature profiles between the pristine and defective panels was shown to be a reliable indicator of damage within most locations. Experimental testing revealed that the MSCdifference profile can be used to accurately detect the location of delamination damage along the skin/stiffener bond-line. The MSC-difference profile method was also shown to detect localised porosity along the bond-line, however its location could not be accurately determined. The sensitivity of the MSC-difference method to damage was highest with the analysis of the lowest vibration mode, and using higher order modes caused a progressive loss in damage resolution. A parametric study using a validated FE model revealed that the MSCdifference method can be used to detect delamination cracking and porosity within any location of the stiffened panel where the local stiffness is high, such as the skin/flange connection or web. However, the method cannot identify damage in low stiffness locations such as the $\Delta$-fillet. Finite element analysis and experimental testing also revealed that the point where the vibrational waves are transmitted into the panel does not significantly alter the resolution of the MSC-difference profile.

\section{Acknowledgements}

The authors kindly acknowledge the financial support of Boeing Aerostructures Australia. The guidance and assistance of RMIT technical staff P. Tkatchyk and R. Ryan in specimen preparation and experimentation is gratefully acknowledged.

\section{References}

[1] Herszberg I, Li HCH, Dharmawan F, Mouritz AP, Nguyen M, Bayandor J. Damage assessment and monitoring of composite ship joints. Composite Structures 2005;67(2):20516.

[2] Tong L, Steven GP. Analysis and Design of Structural Bonded Joints. Kluwer Academic Publishers: Boston, USA; 1999. 
[3] Dharmawan F, Thomson RS, Li HCH, Herszberg I, Gellert E. Geometry and damage effects in a composite marine T-joint. Composite Structures 2004;66(1-4):181-7.

[4] Li HCH, Weis M, Herszberg I, Mouritz AP. Damage detection in a fibre reinforced composite beam using random decrement signatures. Composite Structures 2004;66:159-67.

[5] Hwang D-G. The proof testing and fatigue behavior of graphite/epoxy laminate.

Washington University: St. Louis, MO, USA; 1982.

[6] Kesavan A, Deivasigamani M, John S, Herszberg I. Damage detection in T-joint composite structures. Composite Structures 2006;75:313-20.

[7] Ling H-Y, Lau K-T, Cheng L, Jin W. Fibre optic sensors for delamination identification in composite beams using a generic algorithm. Smart Materials and Structures 2005;14(1):28795.

[8] Okafor AC, Chandrashekhara K, Jiang YP. Delamination prediction in composite beams with built-in piezoelectric devices using modal analysis and neural network. Smart Materials and Structures 1996;5(3):338-47.

[9] Valdes SHD, Soutis C. Delamination detection in composite laminates from variations of their modal characteristics. Journal of Low Frequency Noise and Vibration and Active Control 2000;19(1):27-33.

[10] Chattopadhyay A, Kim HS, Ghoshal A. Non-linear vibration analysis of smart composite structures with discrete delamination using a refined layerwise theory. Journal of Sound and Vibration 2004;273(1-2):387-407.

[11] Watkins SE, Sanders GW, Akhavan F, Chandrashekhara K. Modal analyis using fibre optic sensors and neural networks for prediction of composite beam delamination. Smart Materials and Structures 2002;11(4):489-95.

[12] Tan P, Tong L. Experimental and analytical identification of a delamination using isolated PZT sensor and actuator patches. Journal of Composite Materials 2007;41(4):477-92. [13] Tan P, Tong L. Multiple delamination detection of composite beam using magnetostrictive patch. AIAA Journal 2006;44(11):2547-51.

[15] Whittingham B, Li HCH, Herszberg I, Chiu WK. Disbond detection in adhesively bonded composites structures using vibration signatures. Composite Structures 2006;75:35163.

[16] White CM. Health monitoring of bonded composite aerospace structures. PhD Thesis, Royal Melbourne Institute of Technology: Melbourne, Australia; 2009.

[17] Herman AP. Developments in structural proof testing methodologies for aircraft composite components. PhD Thesis, Royal Melbourne Institute of Technology: Melbourne, Australia; 2010.

[18] Qiao P, Lestari W, Shah MG, Wang J. Dynamics-based damage detection of composite laminated beams using contact and noncontact measurement systems. Journal of Composite Materials 2007;41(10):1217-52.

[19] Chattopadhyay A, Ghoshal A, Schulz MJ, Thornburgh R, Waldron K. Experimental investigation of damage detection in composite material structures using a laser vibrometer and piezoelectric actuators. Journal of Intelligent Material Systems and Structures 2003;14(August):521-37.

[20] Waldron K, Ghoshal A, Schulz MJ, Sundaresan MJ, Ferguson F, Pai PF, Chung JH. Damage detection using finite element and laser operational deflection shapes. Finite Element in Analysis and Design 2002;38:193-226.

[21] Lestari W, Qiao P, Hanagud S. Curvature mode shape-based damage assessment of carbon/epoxy composite beams. Journal of Intelligent Material Systems and Structures 2007;18:189-208.

[22] Pandey AK, Biswas M, Samman MM. Damage detection from changes in curvature mode shapes. Journal of Sound and Vibration 1991;145(2):321-32. 
[23] Staszewski WJ, Lee BC, Mallet L, Scarpa F. Structural health monitoring using scanning laser vibrometry: I. lamb wave sensing. Smart Materials and Structures 2004;13(2):251-60.

[24] Mallet L, Lee BC, Staszewski WJ, Scarpa F. Structural health monitoring using scanning laser vibrometry: II. Lamb waves for damage detection. Smart Materials and Structures 2004;13(2):261-9.

[25] Leong WH, Staszewski WJ, Lee BC, Scarpa F. Structural health monitoring using scanning laser vibrometry: III. Lamb waves for fatigue crack detection. Smart Materials and Structures 2005;14(6):1387-95.

[26] Staszewski WJ, Mahzan S, Traynor R. Health monitoring of aerospace composite structures - active and passive approach. Composites Science and Technology 2009;69(1112):1678-85.

[27] Gao Y, Spencer Jr. BF, Bernal D. Experimental verification of the flexibility-based damage locating vector method. Journal of Engineering Mechanics 2007;133(10):1043-9.

[28] Lu Q, Ren G, Zhao Y. Multiple damage location with flexibility curvature and relative frequency change for beam structures. Journal of Sound and Vibration 2002;253(5):1101-14. [29] D'Cruz J, Herszberg I. Damage detection based on the signature of the structural response to random excitation. 7th International Workshop on Structural Health Monitoring; Stanford, CA, USA, 9-11 September 2009.

[30] Ratcliffe CP, Crane RM, Gillespie JW. Damage detection in large composite structures using a broadband vibration method. British Institute of Non-Destructive Testing 2004;46(1):10-6.

[31] Ratcliffe C, Heider D, Crane R, Krauthauser C, Yoon MK, Gillespie Jr. JW. Investigation into the use of low cost MEMS accelerometers for vibration based damage detection. Composite Structures 2008;82:61-70.

[32] Sung D-U, Kim C-G, Hong C-S. Monitoring of impact damages in composite laminates using wavelet transform. Composites Part B: Engineering 2002;33:35-43.

[33] Pearce PJ, Arnott DR, Camilleri A, Kindermann MR, Mathys GI, Wilson AR. Cause and effect of void formation during vacuum bag curing of epoxy film adhesives. Adhesion Science Technology 1998;12(6):567-84.

[34] Stone MA. Evaluation of oven-cured, solid carbon/epoxy composite with various porosity levels. Review of Progress in Quantitative Nondestructive Evaluation 2009; 28:102532.

[35] Tong L, Steven GP. Analysis and design of structural bonded joints. Dordrecht: Kluwer Academic Publishers; 1999.

[36] Cytec. FM 300 high-shear strength modified epoxy film adhesive. Technical Datasheet. Arizona: Cytec Engineered Materials Inc.; 2005. 
Table 1: Material properties of the unidirectional carbon fibre/epoxy laminate and epoxy adhesive used in the FE modelling of the T-stiffened panels [35-36].

\begin{tabular}{|l|l|l|}
\hline \multicolumn{1}{|c|}{ Material } & \multicolumn{1}{c|}{ Property } & \multicolumn{1}{c|}{ Value } \\
\hline Carbon/epoxy & In-plane Young's modulus $\left(\mathrm{E}_{11}\right)$ & $156.5 \mathrm{GPa}$ \\
\hline Carbon/epoxy & Transverse Young's modulus $\left(\mathrm{E}_{22}, \mathrm{E}_{33}\right)$ & $15.7 \mathrm{GPa}$ \\
\hline Carbon/epoxy & Poisson's ratio $\left(\mathrm{v}_{12} ; \mathrm{v}_{23} ; \mathrm{v}_{31}\right)$ & $0.32 ; 0.35 ; 0.032$ \\
\hline Carbon/epoxy & Shear modulus $\left(\mathrm{G}_{12} ; \mathrm{G}_{23} ; \mathrm{G}_{31}\right)$ & $5.2 ; 1.53 ; 5.2 \mathrm{GPa}$ \\
\hline Epoxy adhesive & Young's modulus $(\mathrm{E})$ & $2.5 \mathrm{GPa}$ \\
\hline Epoxy adhesive & Poisson's ratio $(\mathrm{v})$ & 0.36 \\
\hline Epoxy adhesive & Shear modulus $(\mathrm{G})$ & $0.93 \mathrm{GPa}$ \\
\hline
\end{tabular}


(a)

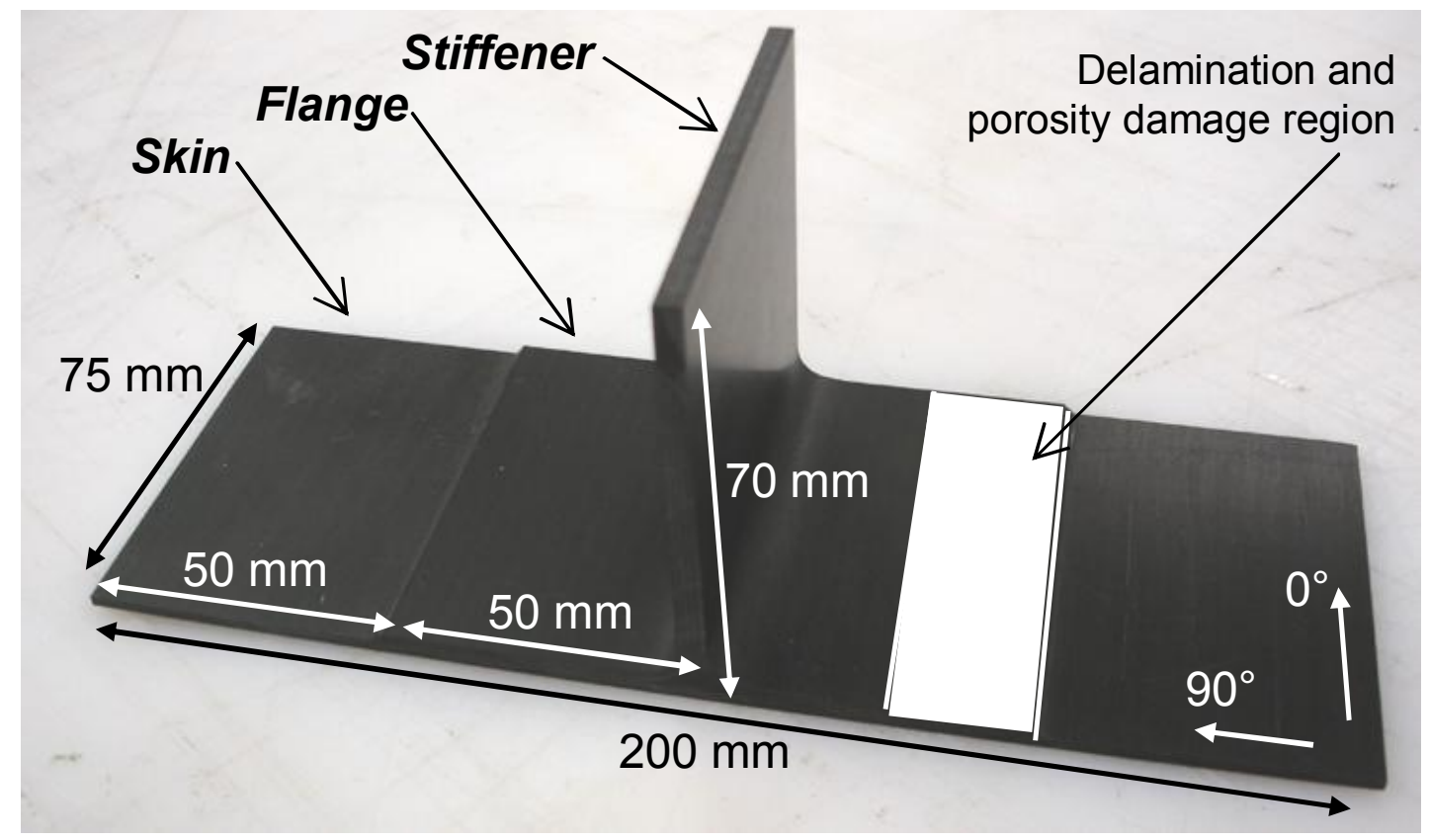

(b)

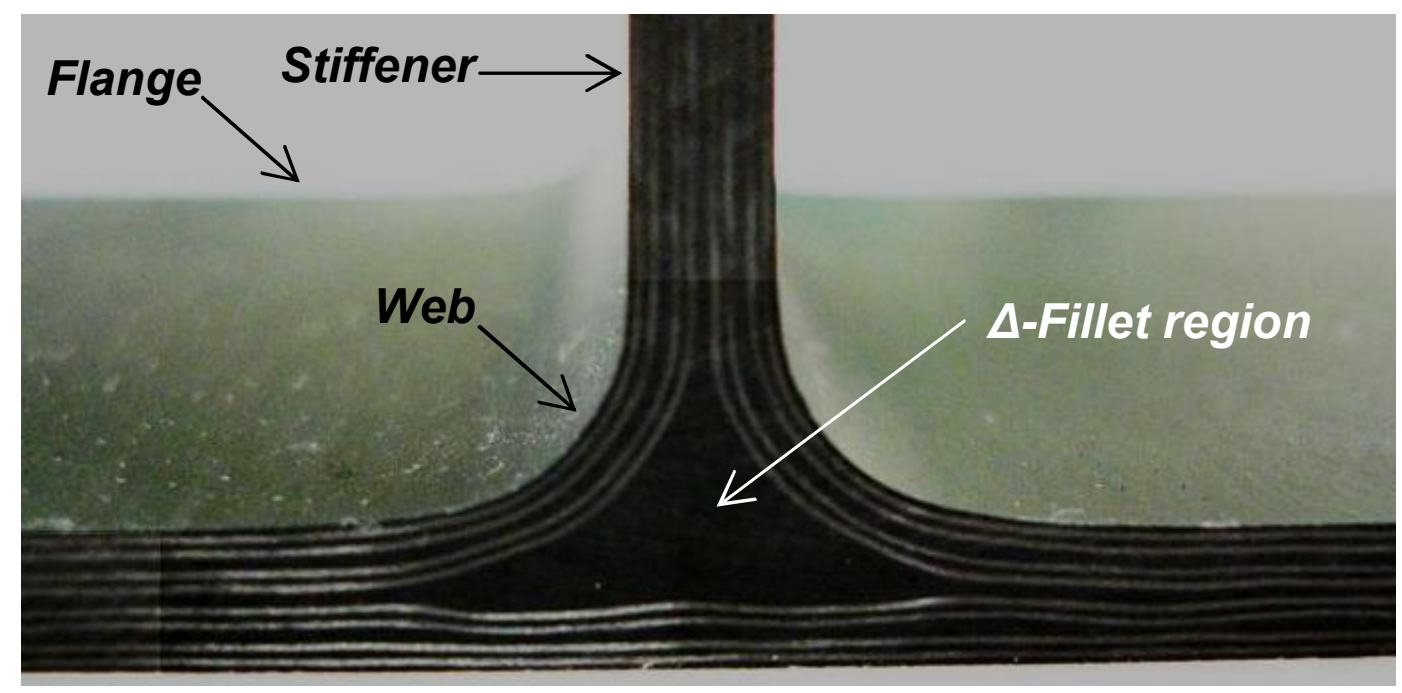

Figure 1: (a) T-joint specimen showing the location of delamination damage or porosity along the interface between the skin and flange; (b) $\Delta$-fillet region at the centre of the T-joint. 
(a)

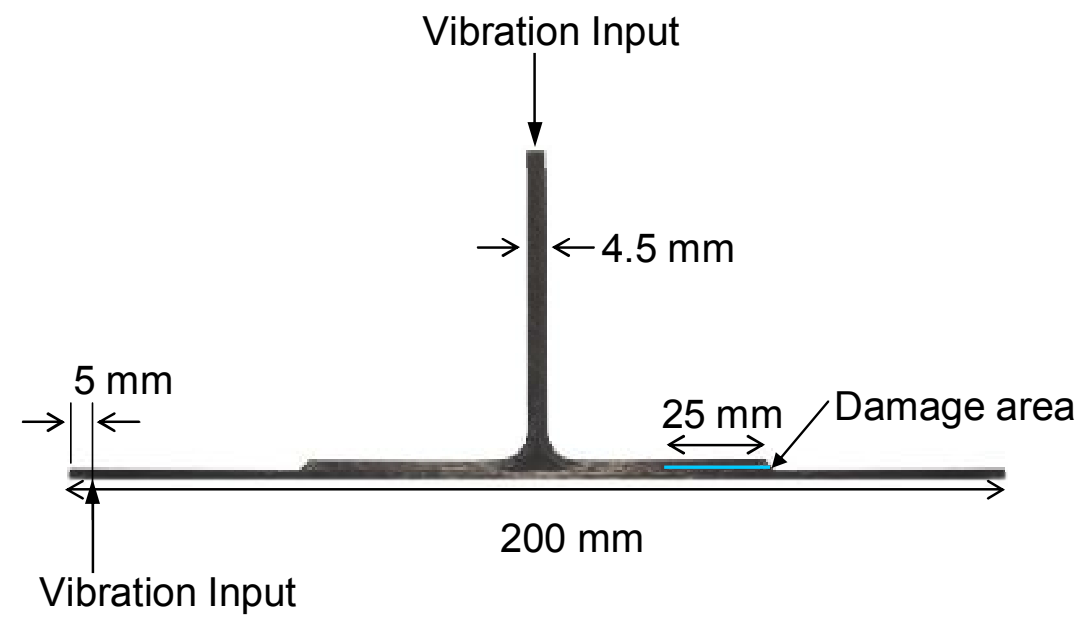

(b)

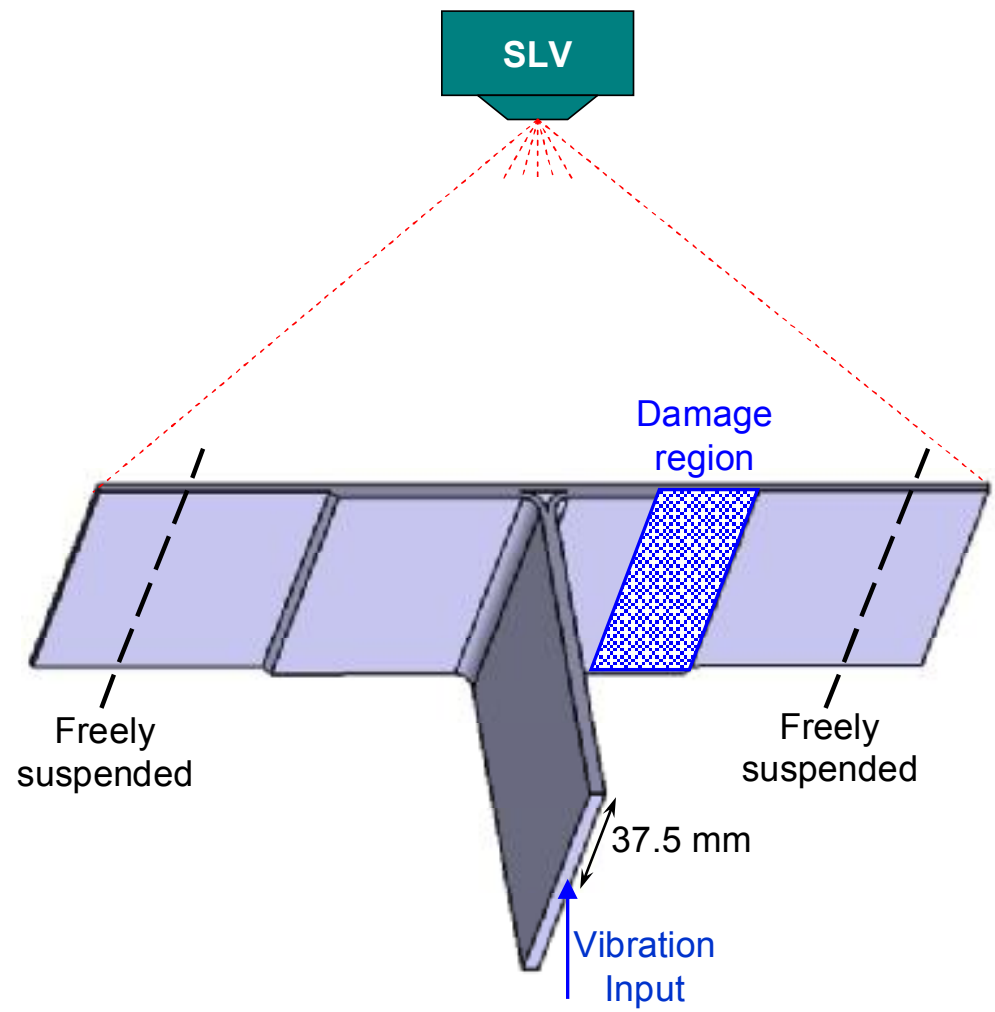


(c)

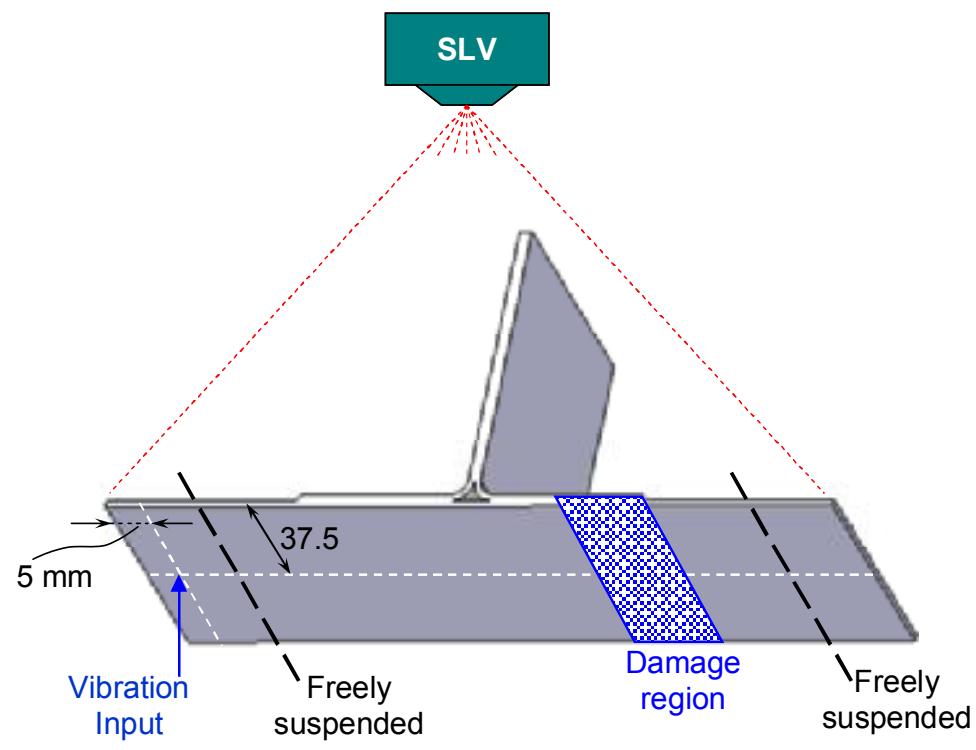

Figure 2: (a) Side-view of the testing arrangement for the T-stiffened panel showing dimensions, damaged area, and where the specimen was excited. SLV measurements were performed from the (b) skin side and (c) stiffener side of the panel.

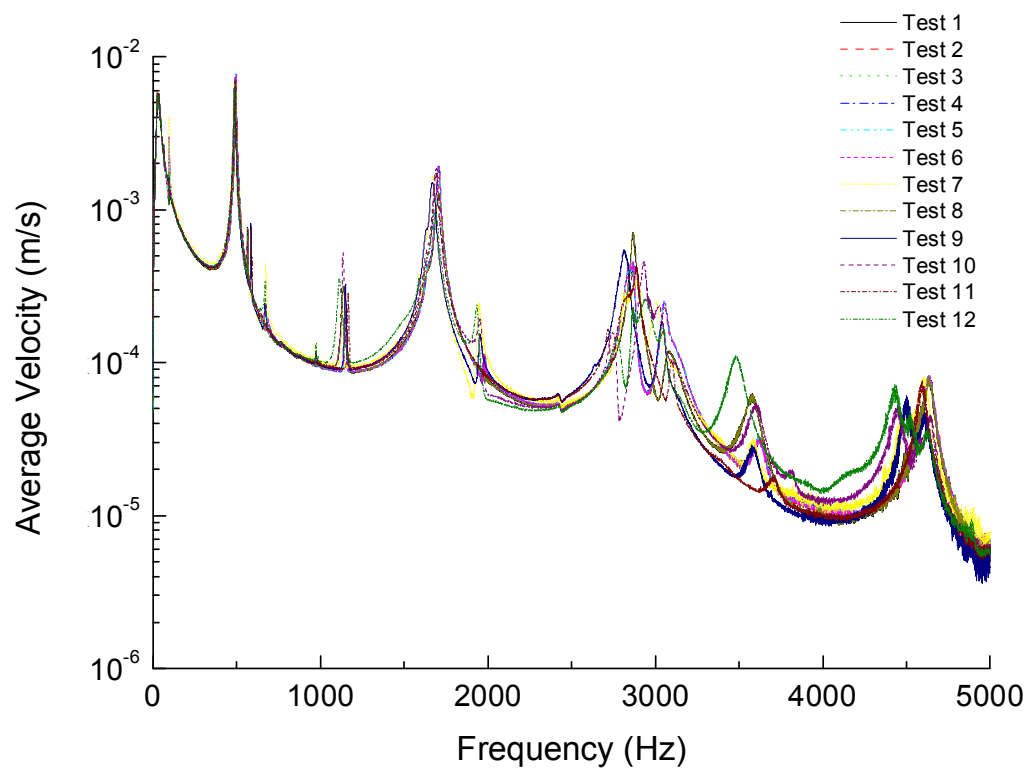

Figure 3: Multiple (12) frequency-velocity spectrum measured for the pristine panel showing good repeatability in the measurements. 
(a)

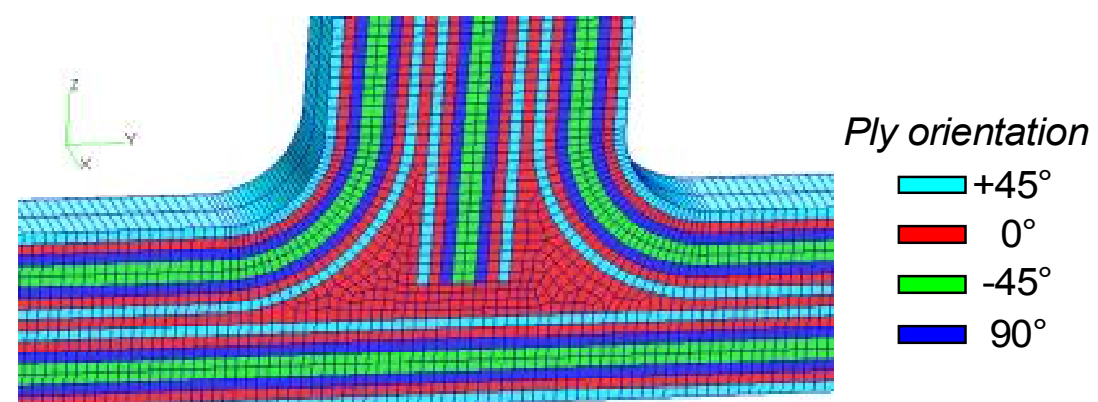

(b)

Ply orientation

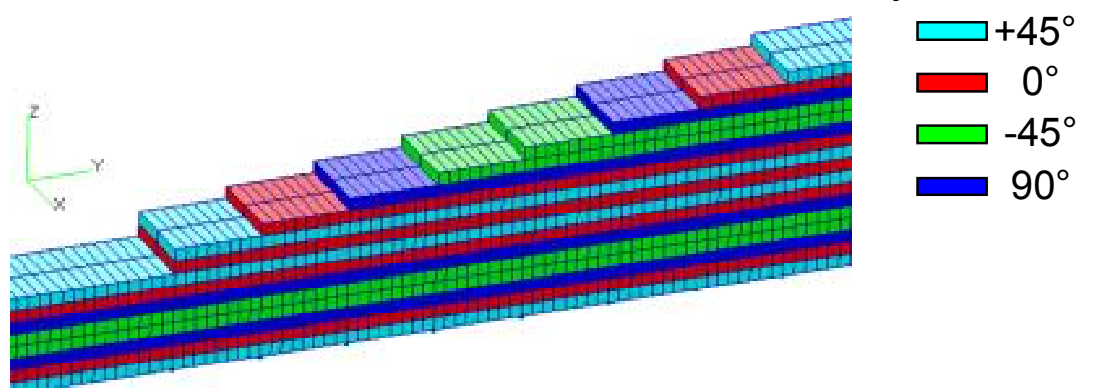

Figure 4: Sections of the FE model of the T-stiffened panel showing close-up views of the (a) web region and (b) taper run-out region to the flange. 


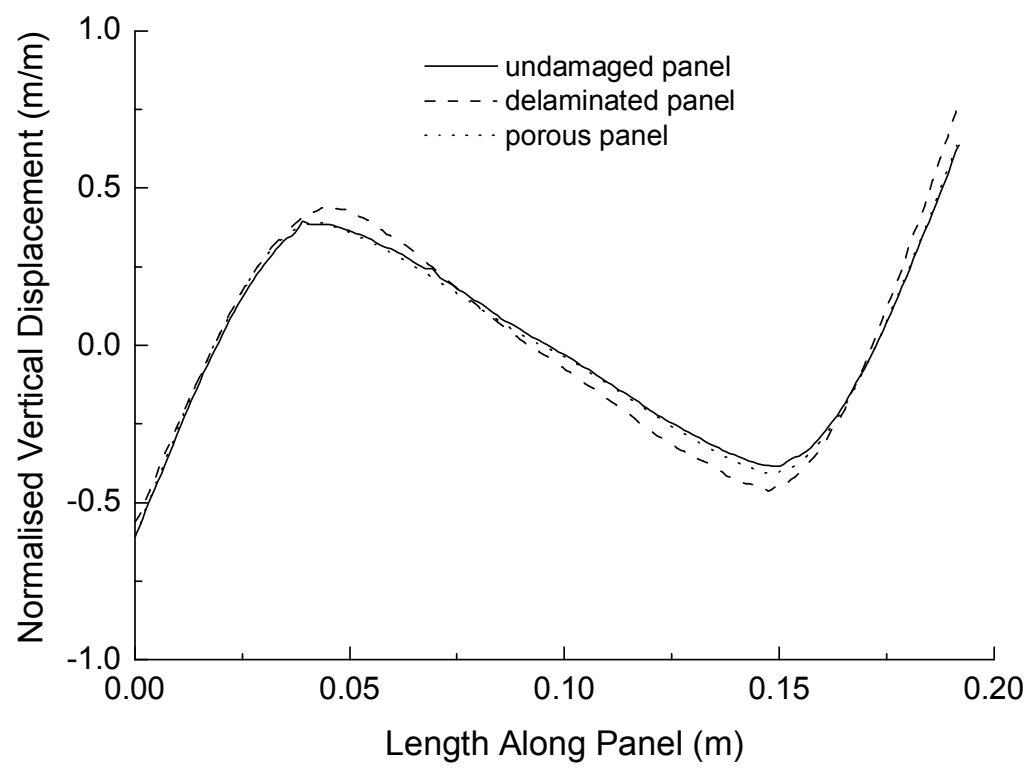

Figure 5: Mode shape displacement profiles along the length of the stiffened panel. The delamination damage and porosity were located at the end of the skin/stiffener taper (refer to the specimen shown in Figure 1). The SLV measurements were performed from the skin side. 
(a)

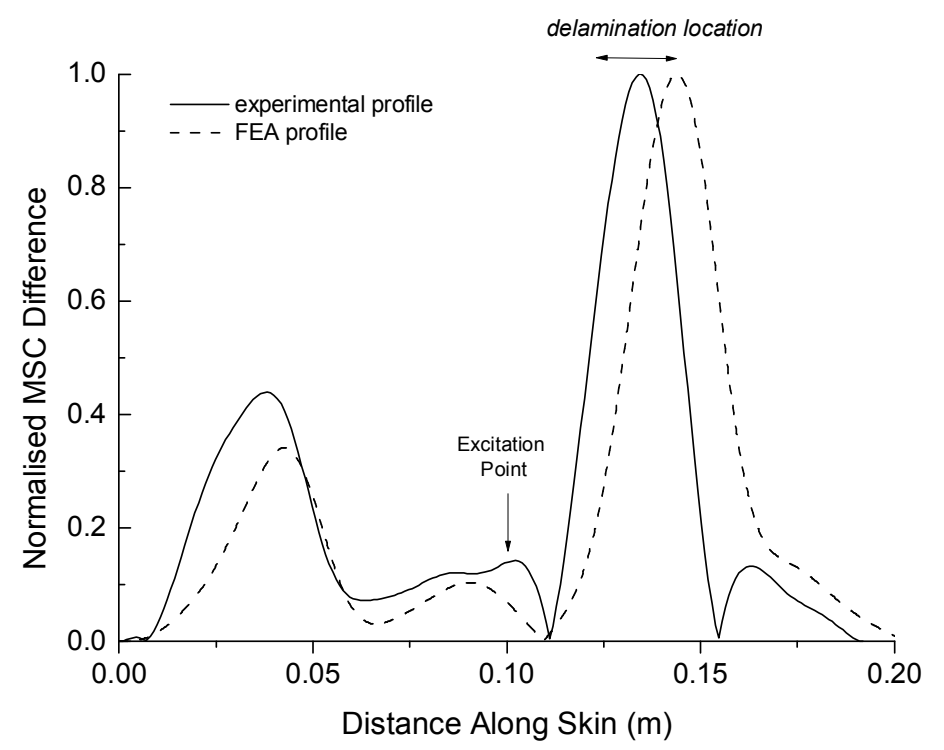

(b)

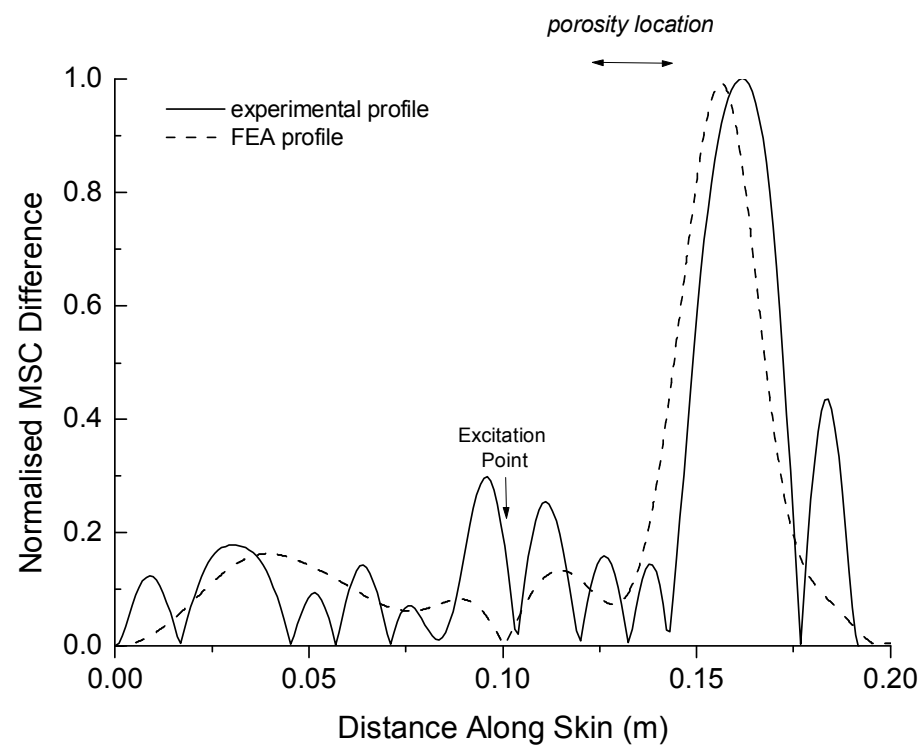

Figure 6: Normalised MSC-difference profiles along the length of the stiffened panels containing (a) delamination or (b) porous region. The profiles were determined for the mode 1 vibrational wave along the skin side of the panels. The solid and dashed curves are the profiles measured experimentally using SLV and calculated using the FEM, respectively. The excitation location where the vibrational waves were transmitted into the panels is indicated. 
(a)

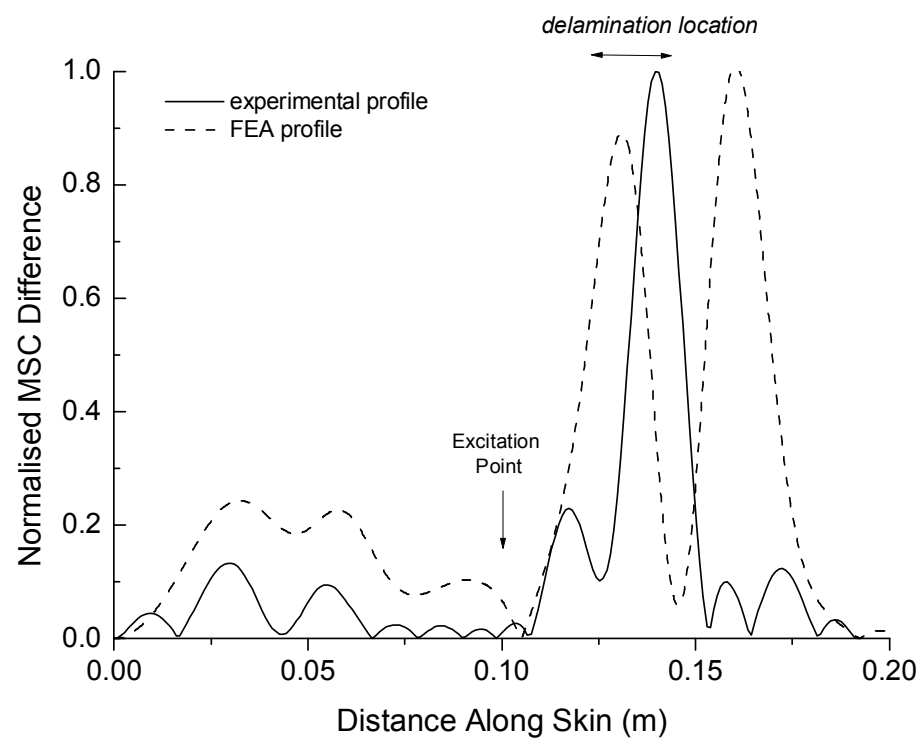

(b)

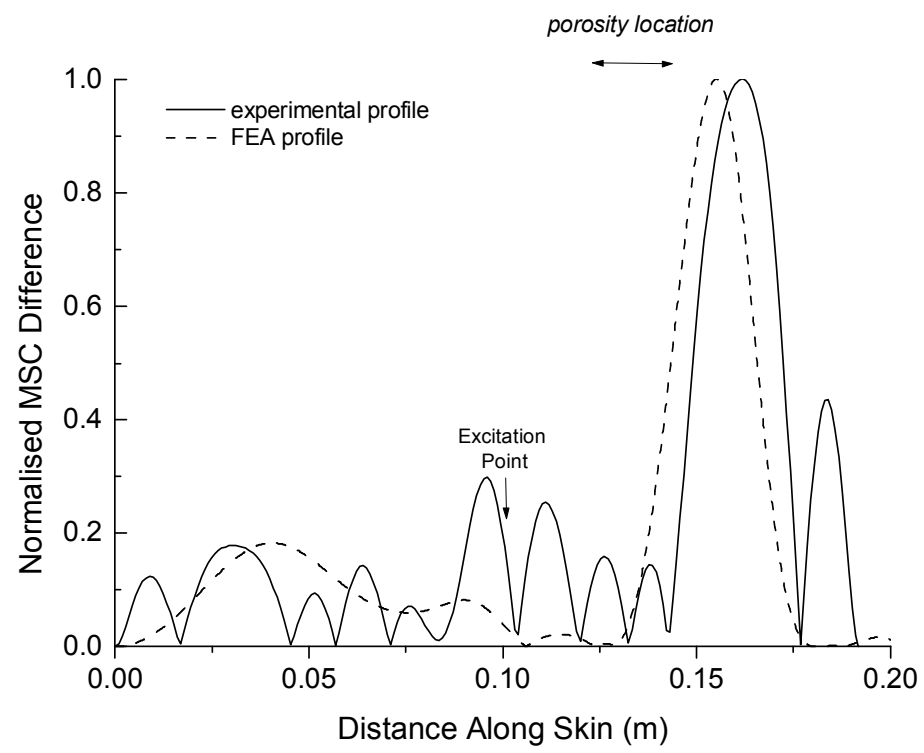

Figure 7: MSC-difference profiles along the length of the stiffened panels containing (a) delamination or (b) porous region. The profiles were determined for the mode 1 vibrational wave along the stiffener side of the panels. The solid and dashed curves are the profiles measured experimentally using SLV and calculated using the FEM, respectively. The excitation location where the vibrational waves were transmitted into the panels is indicated. 
(a)

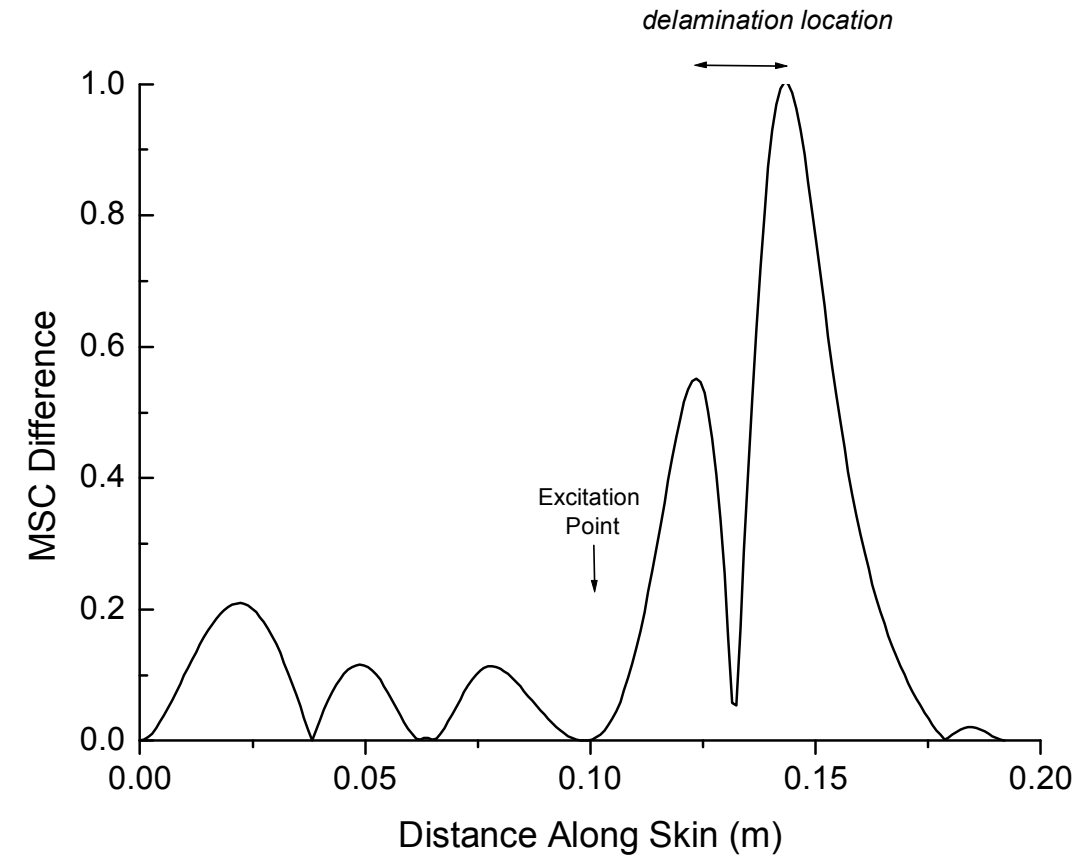

(b)

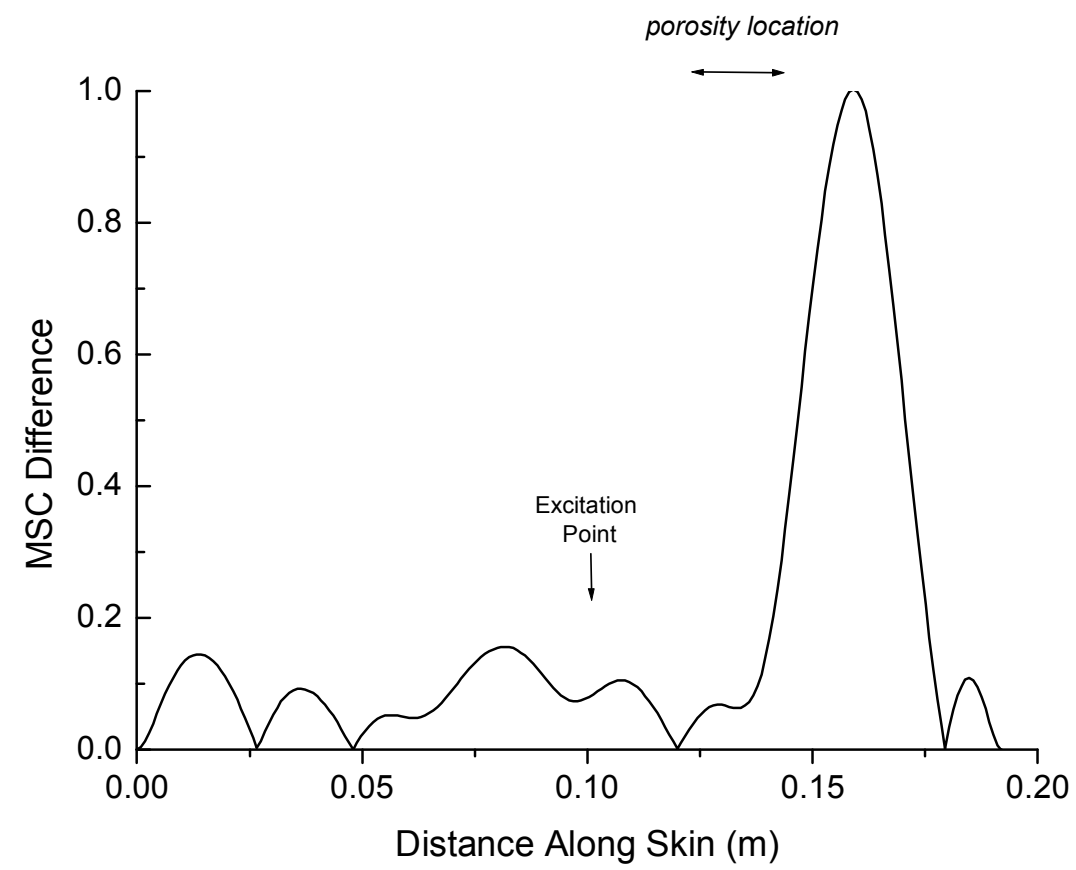

Figure 8: MSC-difference profiles along the length of the stiffened panels containing (a) delamination or (b) porous region. The profiles were determined for the mode 3 vibrational wave along the skin side of the panels. The location where the vibrational waves were transmitted into the panels is indicated. 


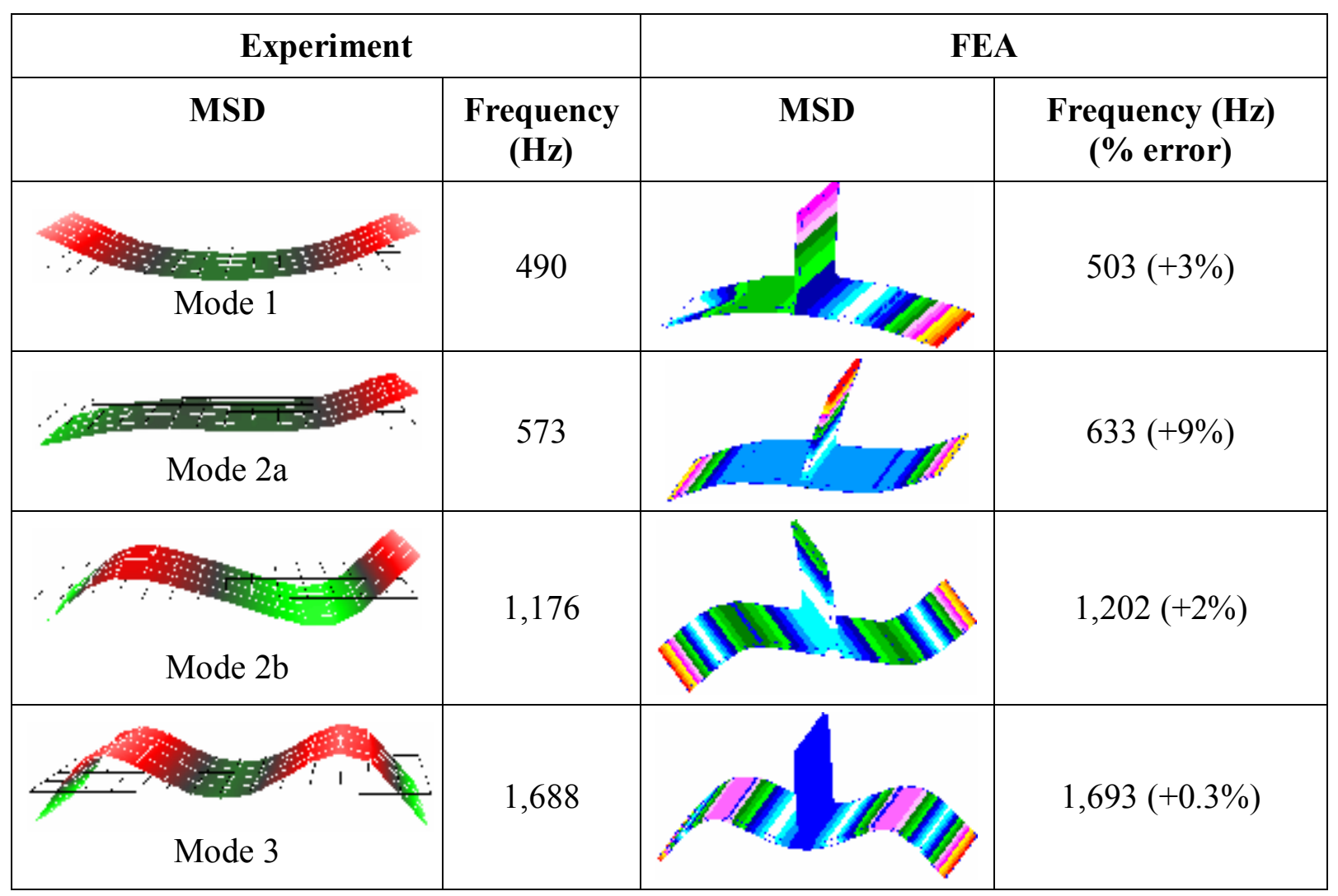

Figure 9: Comparison of the measured (from the skin side) and calculated (FEA) mode shape displacements and frequencies. 
(a)

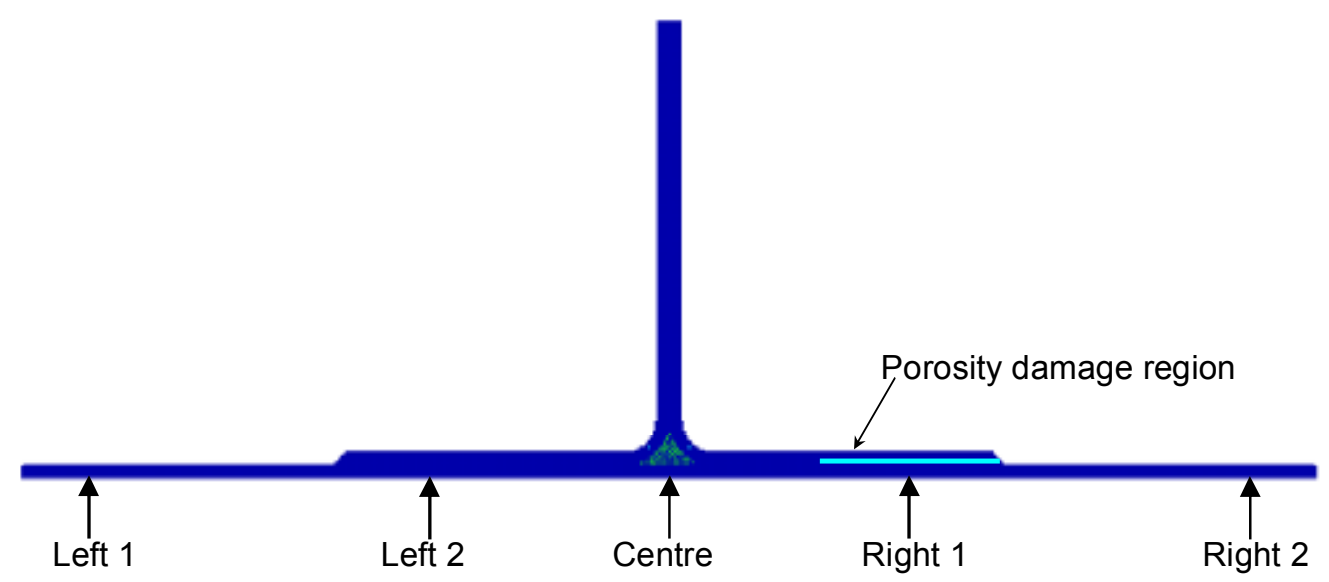

(b)

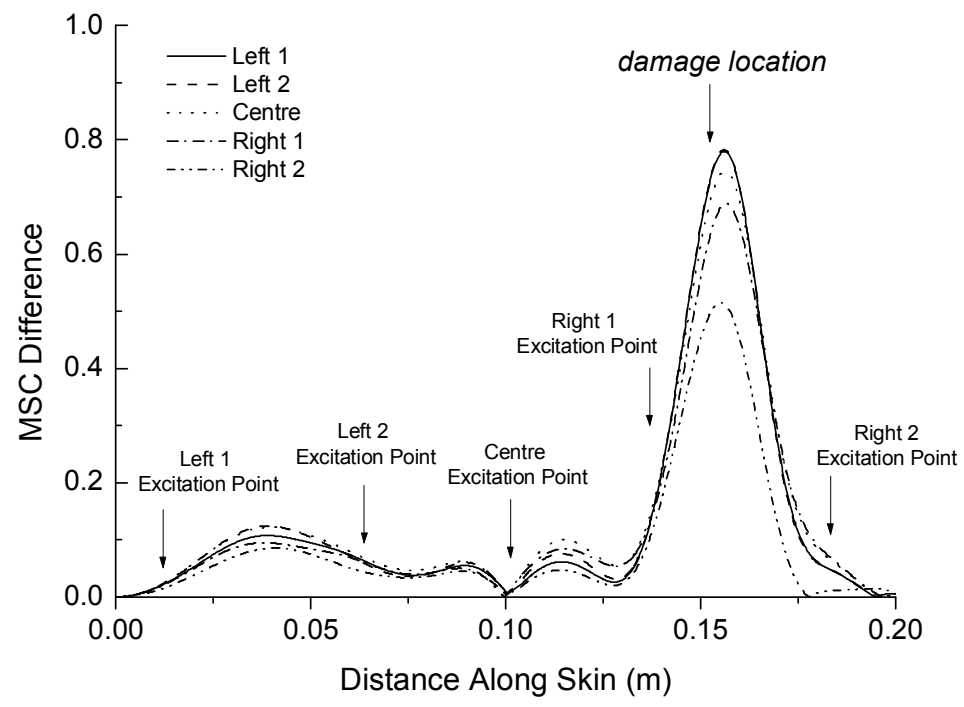

Figure 10: (a) Different vibration input locations along the skin of the stiffened panel containing edge damage. (b) MSC-difference profiles for the different input locations for the panel containing edge porosity. 


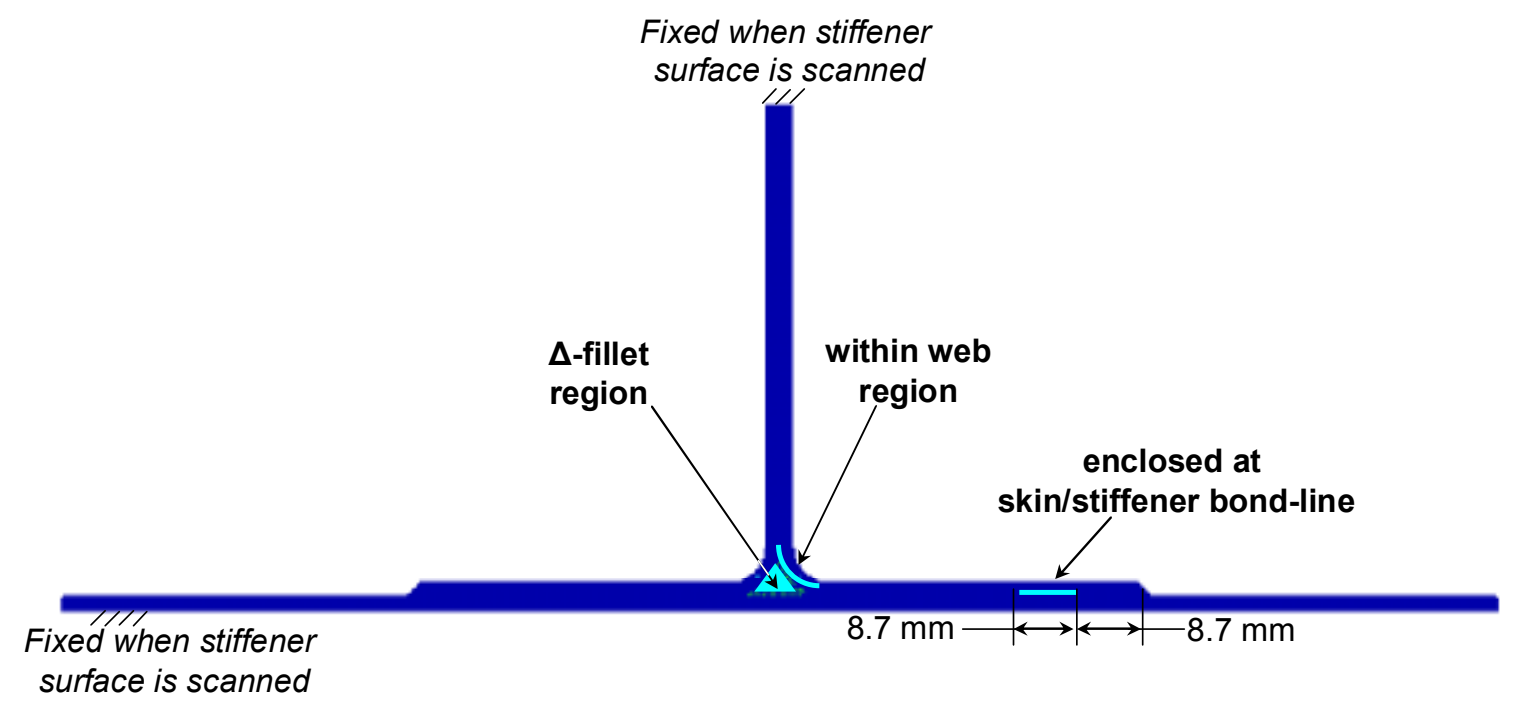

Figure 11: Locations of delamination and porosity damage regions introduced into the finite element model, and associated boundary conditions. 
(a)

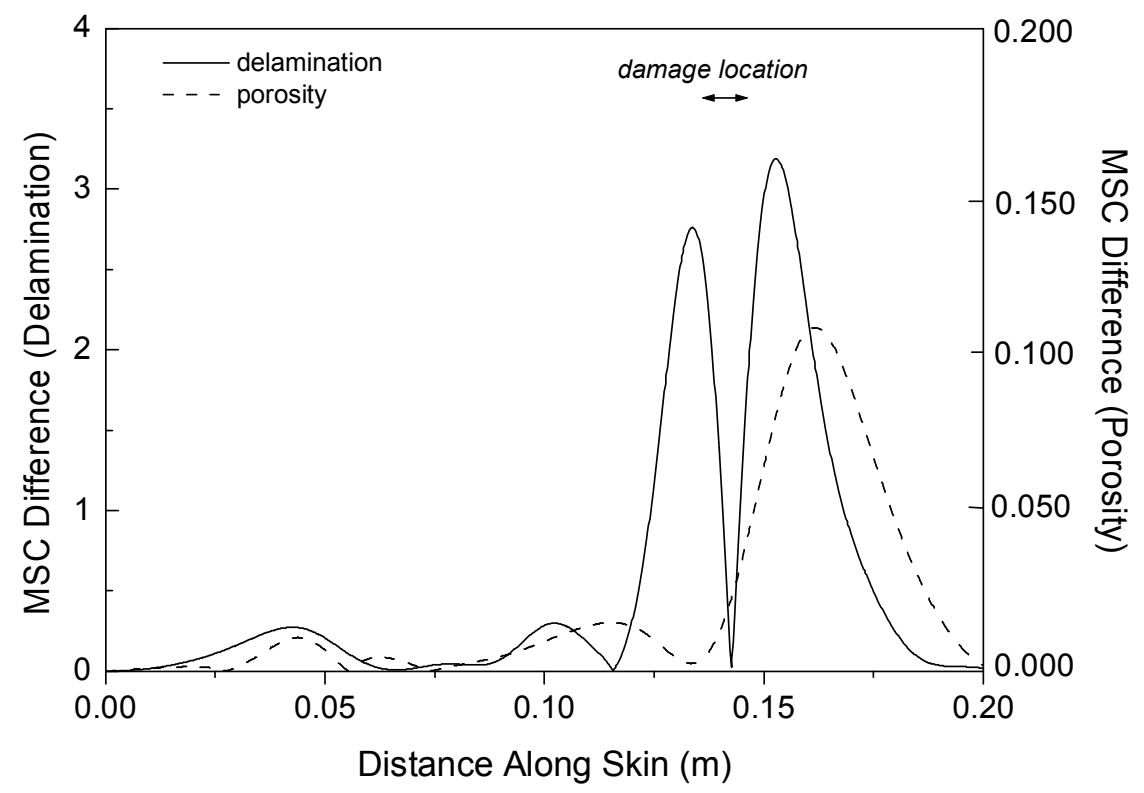

(b)

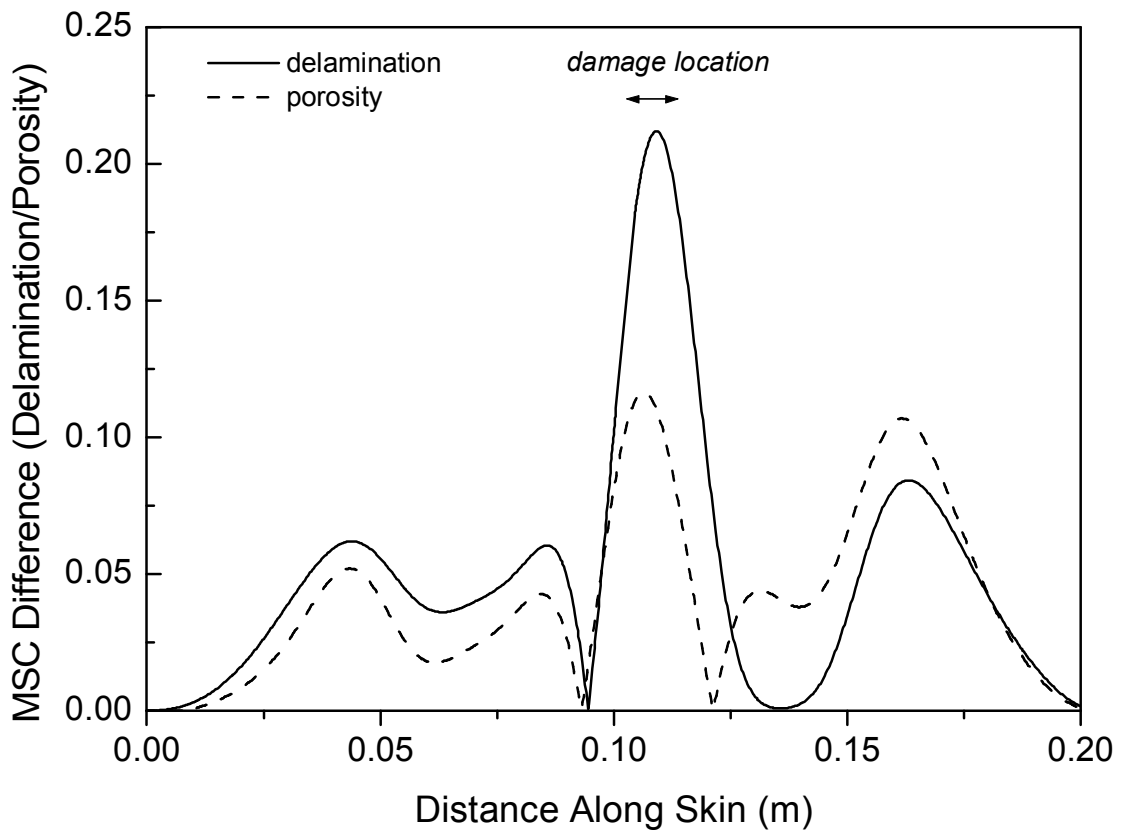


(c)

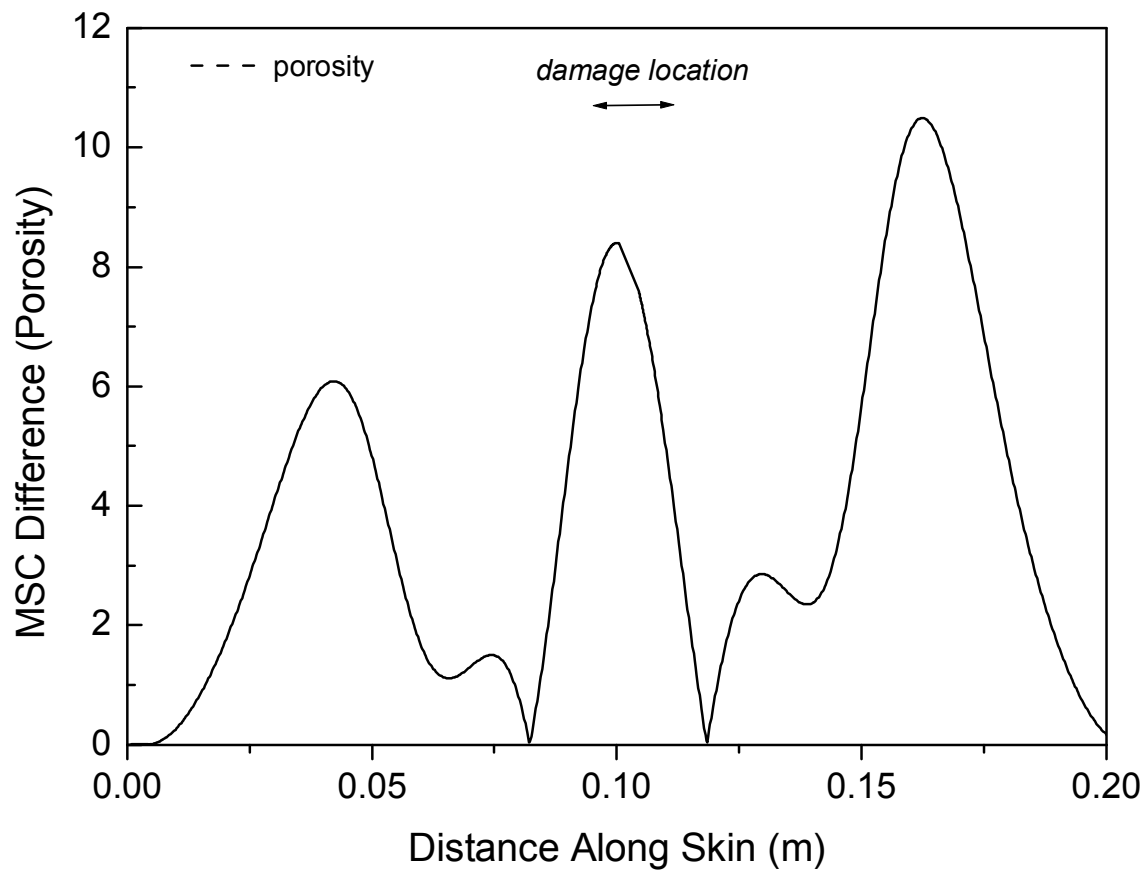

Figure 12: FE predictions of the MSC-difference profiles for delamination and porosity; (a) enclosed damage at the skin/stiffener bond-line, (b) damage within the web, and (c) damage with the $\Delta$-fillet (porosity only). 